\title{
Differentiating cognitive and affective job insecurity: Antecedents and outcomes
}

\author{
GUO-HUA HUANG ${ }^{*}$, XIONGYING NIU ${ }^{2}$, CYNTHIA LEE ${ }^{1,3}$ AND SUSAN J. ASHFORD $^{4}$ \\ ${ }^{1}$ Department of Management, Hong Kong Baptist University, Kowloon, Hong Kong \\ ${ }^{2}$ School of International Business Management, University of International Business \& Economics, Beijing, China \\ ${ }^{3}$ College of Business Administration, Northeastern University, Boston, Massachusetts, U.S.A. \\ ${ }^{4}$ Ross School of Business, University of Michigan, Ann Arbor, Michigan, U.S.A.
}

Summary To test a proposed model of the job insecurity (JI) process that treats cognitive JI and affective JI as separate constructs, this study investigates organizational-level employee involvement and communication practices that influence the level of cognitive JI; increasing levels of cognitive JI in turn can create an affective reaction (i.e., affective JI). This affective reaction then influences individual psychological and behavioral outcomes. With two waves of data from three large Chinese organizations, the model test results show that employee involvement decreases cognitive JI perceptions. This reduction then leads to lower affective JI. Affective JI in turn relates negatively to employee psychological well-being but positively to both supervisor-rated job performance and affective JI six months later. The effect of cognitive JI on employee outcomes is partially through affective JI. Cognitive JI has a direct impact on psychological well-being but not on job performance. These findings offer key theoretical and practical implications. Copyright (C) 2012 John Wiley \& Sons, Ltd.

Keywords: job insecurity; cognitive job insecurity; affective job insecurity; employee involvement; employee communication

The nature of work has changed dramatically along with the worldwide organizational, industrial, and societal shifts that have marked the past three decades (Capelli, 1999), including trends toward increasing levels of employee job insecurity (JI; Lee, Bobko, \& Chen, 2006). JI thus has become an increasingly prominent focus for both practitioners and scholars, considering its significant impact on individual and organizational outcomes, such as employee wellbeing, job satisfaction, absenteeism, turnover, and job performance (Ashford, Lee, \& Bobko, 1989; Sverke, Hellgren, \& Näswall, 2002). To date, most management researchers have focused on the nature of the JI construct, its operationalization and measurement, and its relationships with organizational and individual outcomes in diverse contexts (Sverke et al., 2002). To deepen their understanding of JI though, researchers also need to investigate its contextual antecedents and potential mediators. For example, JI often results from environmental signals within the firm, such as downsizing, restructuring, or layoffs (Lee et al., 2006). Insights into these contextual factors and process mediators could help identify measures that organizations can take to prevent the negative impacts of JI. We therefore examine the role of organizational contextual factors on employees' perceptions of and experiences with JI.

Another important gap in JI research involves the potential distinction between cognitive and affective JI. Cognitive JI refers to an awareness of the possibility of job or benefit loss; affective JI is the emotional experience of being worried or emotionally distressed about these potential losses. Although this distinction has been noted (Borg \& Elizur, 1992; Cheng \& Chan, 2008; Probst, 2003; Reisel \& Banai, 2002), little empirical work has examined its importance (Huang, Lee, Ashford, Chen, \& Ren, 2010). For example, the most widely accepted

*Correspondence to: Guo-Hua Huang, Department of Management, Hong Kong Baptist University, Kowloon, Hong Kong. E-mail: mnhgh@ @kbu.edu.hk 
definition of JI characterizes it as "perceived powerlessness to maintain desired continuity in a threatened job situation" (Greenhalgh \& Rosenblatt, 1984, p. 438), which is clearly a cognitive version of the variable that ignores the very real affective reactions that people have to perceptions of job changes. Huang et al. (2010) highlight the theoretical and practical importance of considering cognitive and affective JI as two separate constructs and offer empirical evidence in support of their arguments. Following their suggestions, we treat cognitive JI and affective JI as separate constructs; we also examine their discriminant validity by investigating the varying contextual antecedents that influence them and the individual and organizational consequences that result from the two forms of JI. We extend the finding of Huang et al. (2010) that affective JI mediates the effect of cognitive JI on outcomes by testing the proposition for two new dependent variables: employee well-being and supervisor-ranked job performance. In addition, we propose and examine the indirect effect of organizational practices on the level of affective JI through cognitive JI. Essentially, we propose that in addition to the influence of affective reactions, cognition plays a role, such that it mediates the relationship between context perceptions and the creation of affect.

\section{Theoretical Background and Hypotheses}

Any form of organizational or involuntary change tends to cause employees to feel uncertain about their future relationship with employers (Ashford et al., 1989). Cognitive JI is a type of stress that stems from employees' perceptions of possible job changes. In Folkman and Lazarus's (1985) process model of the cognitive and emotional mechanisms involved in stress reactions, they define stress as the "relationship between the person and the environment that is appraised by the person as relevant to his or her well-being and in which the person's resources are taxed or exceeded" (p. 152; see also Lazarus \& Folkman, 1984). This definition suggests that a cognitive appraisal of environmental threats (e.g., mergers, downsizing, new technologies) can produce stress in organizations. Consistent with this argument, Ashford et al. (1989) and Lee et al. (2006) demonstrate that organizational change predicts employees' perceptions of cognitive JI.

This conceptualization reflects the cognitive aspect of JI and thus is distinct from affective aspects of JI (Huang et al., 2010). That is, the awareness of a potential job loss differs from the emotional experience of being worried or emotionally concerned about this change. The cognitive judgment of JI likely relates to but is not the same as an emotional reaction to such insecurity. This distinction is helpful for the further conceptual development of the JI construct and has important implications for practitioners for their understanding and management of JI effects. Conceptually, it also is consistent with the stress versus strain distinction in stress literature. Appraisal theories of emotion (e.g., Frijda, 1993; Lazarus, 1999; Roseman, 1991) emphasize the cognitive determinants of emotions, leading stress literature to recognize the importance of both cognitive and affective aspects-a distinction that JI literature has largely ignored.

Instead, most JI studies focus on cognitive rather than affective conceptualizations. Some JI measures contain both cognitive and affective items (e.g., De Witte, 2000; Hellgren, Sverke, \& Isaksson, 1999; Johnson, Messe, \& Crano, 1984), which makes it difficult to tease out their effects and differential predictors. Although a few researchers have measured affective JI, limited attention centers on the construct validity of affective JI (for a review, see Huang et al., 2010). In general, using various measures, researchers have concurred that cognitive JI and affective JI are associated but differ in their outcomes (e.g., Borg \& Elizur, 1992; Ito \& Brotheridge, 2007; König $\&$ Staufenbiel, 2006). Even in the few studies on the effects of affective JI, the results have been mixed; thus, more studies clearly are needed to examine the separate conceptualization and impact of cognitive and affective JI.

Borrowing from psychological contract breach literature (Morrison \& Robinson, 1997), cognitive JI may be analogous to psychological contract breaches, in that a breach refers to the cognitive evaluation that the organization is failing to fulfill its obligations to the employee. Affective JI is similar to psychological contract violation or the affective state that follows from the breach. Using this evidence, Huang et al. (2010) focus on the theoretical distinction between cognitive JI and affective JI and develop a scale to measure affective JI, which partially explains the 
effect of cognitive JI on employees' job satisfaction, organizational commitment, and somatic well-being. However, their study is correlational, as were other previous studies on affective JI. In contrast, we use a time-lagged design to further examine the validity of the affective JI construct and its measure. Specifically, we propose that cognitive JI and affective JI are associated but differ in their associations with both predictors and consequences.

\section{Organizational communication and employee involvement and job insecurity}

Consistent with stress literature (Lazarus \& Folkman, 1984), Greenhalgh and Rosenblatt (1984) assert that JI reflects the transformation of information and objective facts about an environment into particular thought processes. These thought processes can be influenced by both personal and contextual influences. Most researchers have focused on individual differences, such as locus of control and negative affectivity (Roskies, Louis-Guerin, \& Fournier, 1993). However, De Whitte (2005) argues that JI perceptions largely result from the "objective" conditions in which people work; macro-level antecedents such as national unemployment rates (Natti, Happonen, Kinnunen, \& Mauno, 2005) or organizational change (Lee et al., 2006) can be just as important as, if not more important than, individual-level predictors. Therefore, we consider two organizational practice variables and propose that organizational communication and employee involvement, through sharing information and decision-making processes, reduce perceptions of unpredictability and uncontrollability and thereby help minimize JI perceptions.

In particular, we propose that cognitive JI declines if organizations provide more information about crises or changes facing an organization and its employees. This hypothesis has important ramifications for organizations, which often tend to provide less factual information than usual during times of change. Communication during uncertain times tends to be slow, inaccurate, and rhetorical. In a study of realistic information provision following a merger announcement, Schweiger and DeNisi (1991) find widespread failures to communicate. Yet, organizational communication provides information flows to reinforce employees' understanding and helps decrease uncertainty by offering clarity and predictability in people's work environment (Vander Elst, Baillien, De Cuyper, \& De Witte, 2010). Being well-informed about organizational issues (e.g., goals and objectives, new developments, activities, and achievements) thus should affect cognitive JI because it helps make employees feel as if they are valued by the organization (Rhoades \& Eisenberger, 2002). Furthermore, receiving information about personal roles (e.g., expectations, employment conditions, and performance ratings) helps make employees feel less uncertain about their future and the future of their organizations. There is empirical evidence supporting a negative association between organizational communication and JI. For example, Adkins, Werbel, and Farh (2001), in a study with faculty members at an American state university, found that during a financial crisis, perceptions of receiving sufficient and accurate information about the financial crisis was negatively related to JI. Vander Elst et al. (2010), in a cross-sectional study of 3881 employees in Belgium, found that communication with employees was negatively associated with JI. On the basis of the previous arguments and evidence, we therefore propose that when employees believe that the organization communicates important information to them regarding the organization and their personal roles, they experience less cognitive JI.

Employee involvement also has received increasing empirical attention; such practices can create an organizational environment that includes employees in all levels of the firm's decision-making, information-processing, or problemsolving endeavors (Richardson \& Vandenberg, 2005; Wagner, 1994). Involving employees in decisions that traditionally have been limited to management often creates positive changes in employee attitudes and behavior (Leana \& Florkowski, 1992). A widely adopted conceptualization of employee involvement (Lawler, 1992; Lawler, Mohrman, \& Ledford, 1995) characterizes it by the use of practices to share power, knowledge, information, and rewards with lower level employees. Practices to support the sharing of power give subordinates a degree of control or say in decisions that affect their work. The sharing of knowledge notion implies support for employees' ongoing skill development through formal training and informal supervisory coaching. When the practice informs employees about company and workgroup goals, as well as performance feedback, it represents sharing of information. Finally, performance-contingent reward systems can link compensation, promotions, and recognition to individual, group, and 
organizational performance. These four attributes appear mutually reinforcing, such that they constitute a collective set of measures of the effect of employee involvement (Lawler, 1986; Vandenberg, Richardson, \& Eastman, 1999).

Lawler (1996) and Lawler et al. (1995) argue that employee inclusion grants them a greater sense of ownership or involvement in their work, a better understanding of how their work can be done most effectively, and insights into management's perspective on business operations (Leana \& Florkowski, 1992). Several studies have considered the direct effects of employee involvement on employees (e.g., job satisfaction and discretionary behavior) or organizational outcomes (e.g., customer satisfaction and financial performance; Kizilos \& Cummings, 1994; Riordan, Vandenberg, \& Richardson, 2005) but without examining the psychological processes that link involvement to employee outcomes. We propose that employee involvement practices have positive effects because they decrease employees' perceived JI. That is, participation opportunities provide employees with more chances to interact with managers, which should reduce uncertainty but increase perceived control. Therefore, they should result in lower JI cognitions.

Organizational communication (H1a) and employee involvement (H1b) relate negatively to cognitive JI.

Both employee involvement and communication practices, as contextual factors, also should affect affective JI indirectly, through employees' cognitive appraisal of the situation. As we noted, the appraisal model of emotions (e.g., Frijda, 1993; Lazarus, 1991, 1999; Roseman, 1984, 1991; Smith \& Ellsworth, 1985) proposes that stressful events get appraised first, and these cognitive processes produce emotional responses. Consistent with this model, we consider cognitive JI an appraisal of the threat of job loss, and affective JI follows from that appraisal process. The effect of the two contextual factors on affect JI is indirect because only when employees perceive the environment as likely to be changed and threatening would they have the feelings of being concerned or worried. When employees have less cognitive JI, their emotional experience differs from that of employees with greater cognitive JI. We thus propose:

There is an indirect effect of organizational communication (H2a) and employee involvement (H2b) on affective JI through cognitive job insecurity.

\section{Job insecurity and employee outcomes}

A growing body of literature suggests that perceptions of JI may have detrimental consequences for the work outcomes and well-being of employees (Ashford et al., 1989; Probst, Stewart, Gruys, \& Tierney, 2007; Rosenblatt, Talmud, \& Ruvio, 1999), as well as for organizational viability (Greenhalgh \& Rosenblatt, 1984; Kets de Vries \& Balazs, 1997). Work is the central means to satisfy economic and social needs for most people; among other things, work provides a source of income, social contacts, and an identity (Sverke et al., 2002). The perceived threat of job changes could include the frustration of need achievement, which would have consequences as detrimental as the job loss itself. Moreover, JI is generally related to lower levels of job performance, job satisfaction, organizational commitment, intention to stay, trust in the organization, and well-being (Sverke et al., 2002). If Lee et al. (2006) are correct that JI is a nearly universal organizational phenomenon, the ability to anticipate and predict such outcomes is critical.

Prior literature has addressed the effect of cognitive JI primarily from two perspectives. According to a social exchange perspective, cognitive JI has a direct effect on individual work outcomes: When the organization appears to be failing to fulfill usual obligations (e.g., providing job security), employees reduce their work efforts and commitment to the organization (Wong, Wong, Ngo, \& Lui, 2005). According to the appraisal theory of emotions, cognitive JI also affects work outcomes indirectly, through its impact on emotional experiences, such as worry or anxiety about job changes. This role of emotional experience as a mediator has been well documented; for example, Spector and Fox (2002) propose a model in which the environment (e.g., organizational practices) flows to perceptions (e.g., cognitive JI) and then to negative emotion (e.g., affective JI) and finally to counterproductive work behaviors. People also undergo different emotional experiences in situations that they perceive as unjust and thus exhibit different psychological and behavioral responses (e.g., Rupp \& Spencer, 2006). Using cross-sectional data from Chinese organizations, Huang et al. (2010) find that affective JI mediates the relationship between cognitive JI and employee job satisfaction, organizational commitment, and somatic complaints. Because affective JI indicates 
worry about the job, it tends to be disruptive, with potentially strong psychological and behavioral impacts (Sverke et al., 2002). Continued anxiety can even reduce psychological well-being.

Although there is consistent evidence for the negative impact of JI on well-being outcomes (Cheng \& Chan, 2008; Sverke et al., 2002), findings on JI and performance relationships are rather mixed. For example, Ashford et al. (1989) argued that employees who do not feel secure about their jobs are more likely to direct their energies toward worrying about their job situation than toward excelling at their assigned tasks, and their job performance suffers as a result. However, they found no significant impact of JI on supervisor-rated over performance of employees. Rosenblatt and Ruvio (1996) found JI had an adverse effect on the perceived performance of schoolteachers. Brockner, Grovner, Reed, and DeWitt (1992) found an inverted U-shape relationship between JI and work effort. Staufenbiel and König (2010) found both positive (direct) and negative (indirect through work attitudes) effects between JI and performance, but the negative effect was stronger than the positive effect. One limitation of prior studies looking at JI-performance relationship is that they mostly used cognitive measures of JI instead of affective measure. Whereas the cognitive JI and job performance relationship may be explained by various psychological processes and affected by various individual and contextual moderators, the affective JI and job performance is more direct. Our argument is based on the affective events theory (Weiss \& Cropanzano, 1996), which suggests certain behaviors are emotional responses to workplace events. According to affective events theory, various workplace stressors are affective events that may generate emotional responses. Accordingly, we view cognitive JI as stressors that trigger affective JI, which in turn leads to behavioral outcomes. Thus, we propose a negative impact of affective JI on job performance, and the impact of cognitive JI on performance is patricianly through its relationship with affective JI. Together, the preceding theoretical perspectives suggest a partial mediation hypothesis:

Affective JI (Time 1) partially mediates the relationships between cognitive JI (Time 1) and Time 2 outcomes pertaining to affective JI (H3a), employee psychological well-being, (H3b) and job performance (H3c).

The present study thus builds on and extends prior work in this area in three ways. First, we examine the effects of two organizational practices in reducing employee JI. Studies examining contextual factors as ways to cope with JI are rare in the literature. Vander Elst et al. (2010) show that organizational communication and participation related negatively to JI, measured by a scale that mixes both cognitive and affective items. Probst (2005) found that participative decision-making moderated the effect of JI perception on employee outcomes. No research has considered the differential effects of organizational communication and involvement practices on the two forms of JI. We propose that the organizational practices affect cognitive JI more directly than they do affective JI, because such practices increase or decrease employees' awareness of JI but do not necessarily increase or decrease JI-related emotions unless employees explicitly believe that they may be losing their jobs.

Second, we examine the construct validity of affective JI, as recently proposed by Huang et al. (2010), by studying its antecedents and consequences, particularly its discriminant validity with cognitive JI. Accordingly, we extend prior work by examining the mediating role of affective JI on the relationships among cognitive JI and affective JI after a period of six months, impaired psychological well-being, and supervisor-rated job performance. We go beyond Huang et al. (2010) by examining how the two forms JI might differentially predict important organizational and individual outcomes.

Third, we propose and test a comprehensive model in one study. By doing so, we get a better understanding of how organizational practices influence employee outcomes through affecting employees' perceptions and experiences of JI.

\section{Method}

\section{Sample and procedure}

We collected two rounds of data from three state-owned enterprises in Beijing, China: a construction firm, a manufacturing firm, and an electronics firm. With the assistance of their respective human resource managers, we 
administered our questionnaires to randomly selected units from each company, covering a variety of job functions. During the first data collection round, we distributed questionnaires to 354 employees in the first firm, 414 in the second, and 149 in the third firm, following a similar procedure in all three companies. On the days we conducted the field surveys, participants gathered in conference rooms on company premises and were asked to complete the questionnaires during their work time. Participation was voluntary. We gave 15RMB ( US\$2.50) each to those who returned the questionnaire. We collected 810 valid questionnaires during the first round of data collection $(327,365$, and 118 from the three firms, respectively), for a response rate of 88 percent. All the questionnaires were coded to enable us to match them with the questionnaires we would collect during the second round of data collection.

Six months later, we again collected data from the employees and their supervisors. We used the same procedure to distribute and collect the questionnaires. We invited employees who participated in the initial survey to complete a second questionnaire during their paid working time; they received an additional 20RMB ( US\$3.00) as an incentive for their continued involvement. Research assistants distributed the supervisor questionnaires to immediate supervisors, again with the help of the human resource managers of the companies. Each supervisor rated between one and six subordinates' job performance. The supervisors also completed the questionnaire during their working time and received 20RMB as an incentive. In total, 491 employees $(211,220$, and 50 from the three companies, respectively) and 146 supervisors $(77,51$, and 18 , respectively) participated in the second round of data collection. To assess the potential for respondent bias, we checked for any differences between respondents who completed both surveys and those who only participated in the first round. These two groups do not differ significantly in terms of their affective JI or demographics, except for gender, $F(1,804)=10.85, p<.01$, and education, $F(1,805)=8.09, p<.01$. We controlled for all demographic variables in all our analyses though. The response rate for Time 2 was 61 percent, and on average, each supervisor rated 3.4 subordinates. We matched the employee and supervisor questionnaires and obtained a final sample size of 462 subordinate-supervisor dyads, with 205, 209, and 48 dyads from the construction, manufacturing, and electronics companies, respectively. In the final sample, 70 percent of the respondents were men, the average age of the respondents is $36-40$ years, 46 percent had a high school education and 28 percent had an associate's or bachelor's degree, 50 percent had less than 5 years of organizational tenure, and 35 percent were regular staff whereas 48 percent were contract-based employees.

\section{Measures}

The first-round questionnaire measured employees' perceptions of organizational involvement practices and shared information, as well as cognitive JI, affective JI, and several demographic (control) variables. Six months later, we measured the outcome variables of affective JI, impaired psychological well-being, and supervisor-rated job performance. All the English-language scales we used were translated into Chinese and then independently translated back into English to ensure equivalence (Brislin, 1980). Chinese language experts also examined the questionnaire to ensure that the items were easily interpretable. Unless indicated otherwise, all the multiple-item measures used a 5-point Likert-type response scale ranging from (1) strongly disagree to (5) strongly agree.

\section{Employee involvement}

Employee perceptions of their involvement in their employing organizations included eight items, adopted from the high-involvement work process measure developed by Vandenberg et al. (1999). The original measure and its later development ("involvement climate," Richardson \& Vandenberg, 2005; Riordan et al., 2005) have been used frequently to gather employees' self-reported perceptions. Two items measure each of the four components of employee involvement: sharing of power/participation (e.g., "I have sufficient authority to fulfill my job responsibilities"), sharing of information (e.g., "Management gives sufficient notice to employees prior to making changes in policies and procedures"), rewards tied to performance (e.g., "There is a strong link between how well I perform my jobs and the likelihood of receiving a raise in pay/salary"), and knowledge/training and development (e.g., "I 
had adequate job-related training"). The Likert-type response scale included seven points, instead of five, but used the same endpoints. The internal consistency reliability of the scale was .85 .

\section{Organizational communication}

We measured employee perceptions of organizational communication by using 15 items from Smidts, Pruyn, and van Riel's (2001) study, including eight items measuring employee perceptions of the adequacy of information shared about organizational issues and seven items pertaining to job-related issues. Sample items are "I have received information about the goals of our organization" and "I have received information about what the manager expects from me." These responses also appeared on a 7-point Likert-type scale from strongly disagree to strongly agree. The internal consistency reliability was .95 .

\section{Cognitive job insecurity}

We adopted the 4-item job future ambiguity measure developed by Caplan, Cobb, French, Van Harrison, and Pinneau (1975) to assess the amount of uncertainty each person perceives about future job and career security (The four items are "1. How certain are you about what your future career picture looks like?" "2. How certain are you that opportunities for promotion and advancement will exist in the next few years?" "3. How certain are you about whether your job skills will be of use and value five years from now?" and "4. How certain are you about what your responsibilities will be six months from now?"). This cognitive measure of JI has been used widely in prior literature (Ashford et al., 1989; Lee, Bobko, Ashford, Chen, \& Ren, 2008). All these items were reverse coded, and the scale achieved an internal consistency reliability of .60. This low alpha value may be a function of the relatively few items in the scale (Bernardi, 1994; Cortina, 1993). Although below the .70 level recommended by Nunnally (1967), this reliability estimate is sufficient to use for research (Hair, Anderson, Tatham, \& Black, 1998; Pierce, Gardner, Dunham, \& Cummings, 1993). Lee et al. (2008) reported similarly low levels of reliability of this measure (.65 and .68) in two of their Chinese samples. Moreover, because low reliability reduces the size of the measures of associations, this value may not be a significant problem in our study if our hypotheses regarding cognitive JI receive support.

\section{Affective job insecurity}

In addition to using the 7-item measure of affective JI of Huang et al. (2010), which they developed from a thorough review of prior literature, we included three items to increase scale reliability. The 10-item scale appears in the Appendix; it produced coefficient alphas of .82 and .86 at Times 1 and 2, respectively.

\section{Psychological well-being}

We used the depression and performance dysfunction subscales from Lee, Jamieson, and Earley (1996), which originally were developed on the basis of Goldberg and Hillier's (1979) General Health Questionnaire. Four items tap severe depression (e.g., "felt that life isn't worth living"), whereas three assess performance dysfunction (e.g., "felt that on the whole you were not doing things well"). Respondents reported, on a 4-point scale, how frequently they had experienced these symptoms in the past few weeks. Because the items were reverse coded (i.e., higher scores indicate lower levels of well-being), we refer to the outcomes as "impaired psychological well-being." The coefficient alpha for this 7 -item scale was .71.

\section{Job performance}

We measured job performance by using the 11-item scale of task performance compiled by Tsui, Pearce, Porter, and Tripoli (1997). Supervisors completed this measure and rated, from low to high (5-point scale), employees' performance on 11 aspects, such as work quantity, quality, efficiency, creativity, and so on. The coefficient alpha was .94 for our sample. 


\section{Control variables}

Finally, we included several demographic variables as controls. For age, we used eight categories: 26-30 years of age, 31-35, 36-40, 41-45, 46-50, 51-55, and 56 years of age and older, which we coded 1 through 8, respectively. We coded men as 0 and women as 1 . For education, we used six categories: middle school and below, high school, associate's degree, bachelor's degree, master's degree, or doctoral degree, coded 1 through 6, respectively. The tenure with the organization measure featured seven categories: less than 6 months, 6 months to 1 year, 1-2 years, 2-5 years, 5-10 years, 10-20 years, and more than 20 years, coded 1 through 7 , respectively. Because different employee positions may induce different perceptions, we also controlled for employment type by categorizing employees as regular staff (1), contract-based (2), or temporary (3). Finally, to control for specific organizational effects in the three firms in our sample, we dummy coded the firms with two dummy variables (dummy1: $1=$ construction, $0=$ manufacturing or electronics; dummy2: $1=$ manufacturing, $0=$ construction or electronics .

\section{Results}

In Table 1, we present the descriptive statistics and zero-order correlations among the study variables. The management practices of employee involvement and employee communication correlate significantly with cognitive JI (involvement $r=-.18, p<.01$; communication $r=-.16, p<.01$ ), in preliminary support of Hypothesis 1 . These practices do not have a significant direct relationship with affective JI (both involvement and communication $r=-.06, n s)$. Cognitive JI relates significantly and positively to Time 1 affective JI $(r=.18, p<.01)$ and Time 2 affective JI $(r=.17, p<.01)$, as well as to impaired psychological well-being $(r=.12, p<.05)$. However, cognitive JI relates only marginally to job performance $(r=-.08, p<.10)$. Affective JI at Time 1 also relates significantly to impaired psychological well-being $(r=.16, p<.01)$ and job performance $(r=-.11, \mathrm{p}<.05)$; we find similar results for affective JI measured at Time 2 (well-being $r=.27, p<.01$; performance $r=-.13, p<.05$ ). We tested whether cognitive JI and affective JI correlate equally with other variables (Steiger, 1980) and found that they correlated differently with the two organizational factors (involvement $z=-2.03, p<.05$; communication $z=-1.69, p<.10$ ), but their correlations with the two outcomes (well-being and performance) do not differ significantly.

Before continuing to test the hypotheses, we checked for data non-independence. That is, we asked each supervisor to rate up to six of his or her subordinates' performance, so we have a nested data structure that may violate regression assumptions. We conducted a one-way analysis of variance for job performance, using supervisor code as the group number. The between-group variance was greater than the within-team variance $(F=2.83$, $p<.01)$. We next calculated ICC(1) and ICC(2) values of .07 and .21 , respectively. The ICC(1) coefficient thus was slightly higher than .05 , but the $\operatorname{ICC}(2)$ coefficient was lower than the cutoff of .50 required for aggregation (James, 1982). In addition, we calculated the design effect (Shackman, 2001) using the following formula: design effect $=1+(k-1) * \operatorname{ICC}(1)$, where $k$ represents the average group size (in our case, 3.4). The coefficient for the design effect was 1.17, below the conventional cutoff of 2 (www.statmodel.com). Therefore, the nested data structure due to supervisor ratings should not present any substantial threats to our findings.

We conducted hierarchical regression analysis to test Hypothesis 1; we provide the results in Table 2. After controlling for all the demographic variables, we found that the two management practices together explained additional variance in cognitive JI $\left(\Delta R^{2}=.05, p<.01\right)$. The coefficient was significant for employee involvement $(\beta=-.20$, $p<.01)$ but not for employee communication $(\beta=-.06, n s)$. Consistent with our expectation, employee involvement and employee communication did not relate significantly to affective JI $(\beta=-.00, n s)$. In Model 2 , we also confirmed the finding of Huang et al. (2010) that cognitive JI related significantly to affective JI $(\beta=.18, p<.01)$.

To test for the indirect effect proposed in Hypothesis 2, we conducted the Sobel test (Sobel, 1982). In their comparison of 14 methods to assess mediation effects, MacKinnon, Lockwood, Hoffman, West, and Sheets (2002) identified the Sobel test as superior in terms of power and intuitive appeal; it provides a direct test of the indirect effect. A bootstrap test recently popularized by Preacher and Hayes $(2004,2008)$ might offer an alternative, superior test 


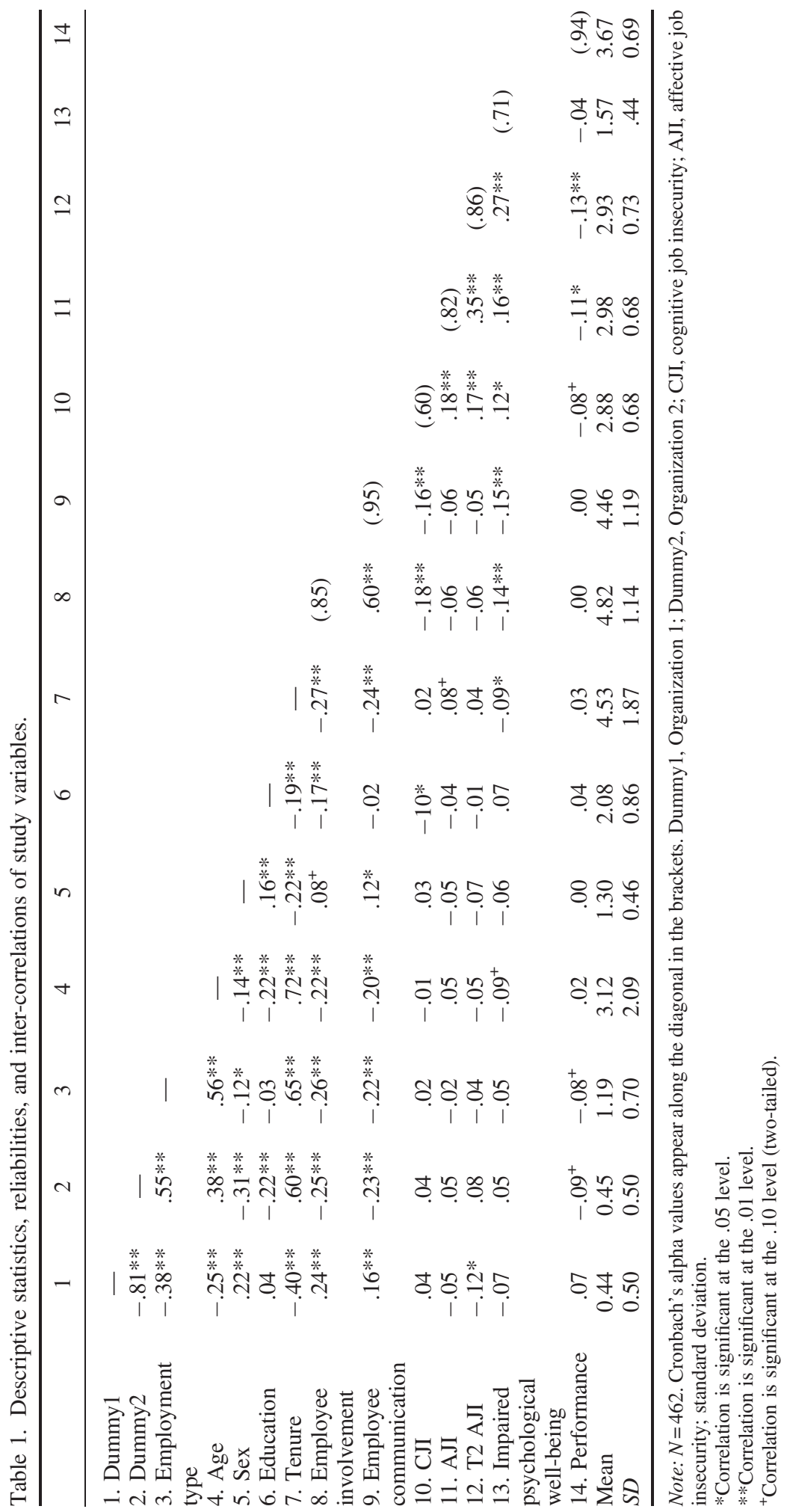


Table 2. Results of hierarchical regression analysis of cognitive job insecurity and affective job insecurity.

\begin{tabular}{|c|c|c|c|c|c|c|}
\hline & \multicolumn{3}{|c|}{ Cognitive JI } & \multicolumn{3}{|c|}{ Affective JI (Time1) } \\
\hline & \multicolumn{3}{|c|}{ Model 1} & \multicolumn{3}{|c|}{ Model 2} \\
\hline & $\beta$ & $\Delta R^{2}$ & $\Delta F$ & $\beta$ & $\Delta R^{2}$ & $\Delta F$ \\
\hline \multicolumn{7}{|l|}{ Step 1} \\
\hline Dummy1 & $.22 * *$ & & & -.09 & & \\
\hline Dummy2 & $.21 *$ & & & -.07 & & \\
\hline Employment type & .09 & & & $-.12^{+}$ & & \\
\hline Age & $-.08 *$ & & & .02 & & \\
\hline Sex & $.07 *$ & & & -.04 & & \\
\hline Education & $-.12 *$ & & & -.01 & & \\
\hline Tenure & .02 & $.03 *$ & $2.06 *$ & .13 & .02 & 1.19 \\
\hline \multicolumn{7}{|l|}{ Step 2} \\
\hline Employee involvement & $-.20 * *$ & & & -.00 & & \\
\hline Employee communication & -.06 & $.05 * *$ & $11.86^{* *}$ & -.00 & .00 & .68 \\
\hline \multicolumn{7}{|l|}{ Step 3} \\
\hline Cognitive JI & & & & $.18 * *$ & $.03 * *$ & $13.54 * *$ \\
\hline
\end{tabular}

Note: $N=462$. Dummy1, Organization 1; Dummy2, Organization 2; JI, job insecurity.

${ }^{*} p<.05 ; * * p<.01 ;{ }^{+} p<.10$ (two-tailed).

though, because of its higher power (Zhao, Lynch, \& Chen, 2010). Therefore, we also used Preacher and Hayes's (2008) macro to test the indirect effects we have proposed.

The results regarding the indirect effect of organizational practices and affective JI (i.e., Hypothesis 2) appear in Table 3. Three paths (i.e., independent variable to mediator, mediator to dependent variable, and independent variable to dependent variable) were significant, and the indirect effect from the independent variable to affective JI through cognitive JI was significant for employee involvement $(Z=-2.05, p<.05$, two-tailed) but not for employee communication. The bootstrap estimates show that the true indirect effect for employee involvement should lie between -.05 and -.01 , with 95 percent confidence. Thus, consistent with the regression results, we find support for Hypothesis 2a in the Sobel and bootstrap tests of indirect effects but not for Hypothesis $2 \mathrm{~b}$.

To test Hypothesis 3, regarding affective JI as a mediator of the cognitive JI-outcomes relationships, we first conducted hierarchical multiple regressions of affective JI at Time 2, impaired psychological well-being, and job performance (Table 4). When cognitive JI and affective JI (Time 1) both entered the regression, cognitive JI predicted affective JI at Time $2(\beta=.13, p<.01)$ and impaired psychological well-being $(\beta=.07, p<.01)$ but not job performance $(\beta=-.06, n s)$. Furthermore, the affective JI at Time 1 significantly predicted all Time 2 outcomes (affective JI $\beta=.34, p<.01$; well-being $\beta=.10, p<.01$; performance $\beta=.11, p<.01$ ).

Table 3. Results of Sobel test and bootstrap test of indirect effect of organizational practices and affective job insecurity through cognitive job insecurity.

\begin{tabular}{lcccccr}
\hline & \multicolumn{9}{c}{ Indirect effect } \\
\cline { 2 - 6 } & & & & \multicolumn{2}{c}{ Bootstrapping (95\% CI) } \\
\cline { 3 - 7 } Independent variable & Effect & $S E$ & $Z$ & $p$ & Lower & Upper \\
\hline Employee involvement & -.02 & 0.01 & 2.05 & .04 & -0.05 & -0.01 \\
Employee communication & -.01 & 0.01 & .93 & .35 & -0.02 & 0.01 \\
\hline
\end{tabular}

Note: $N=462$. SE, standard error; CI, confidence interval. 
Table 4. Results of hierarchical regression analysis of Time 2 outcomes.

\begin{tabular}{|c|c|c|c|c|c|c|c|c|c|c|c|}
\hline \multirow[t]{2}{*}{ Variables } & \multicolumn{2}{|c|}{ AJI (Time 1) } & \multicolumn{3}{|c|}{ AJI (Time 2) } & \multicolumn{3}{|c|}{$\begin{array}{c}\text { Impaired psychological } \\
\text { well-being }\end{array}$} & \multicolumn{3}{|c|}{ Performance } \\
\hline & M1 & M2 & M1 & M2 & M3 & M1 & M2 & M3 & M1 & M2 & M3 \\
\hline \multicolumn{12}{|l|}{ Step 1} \\
\hline Dummy1 & -.07 & -.13 & $-.23+$ & $-.28 *$ & $-.24 *$ & -.02 & -.05 & -.04 & -.02 & .00 & -.01 \\
\hline Dummy2 & -.04 & -.10 & -.06 & -.12 & -.09 & .12 & .09 & .10 & -.18 & -.15 & -.16 \\
\hline Sex & -.04 & -.06 & -.08 & -.09 & -.07 & -.06 & -.07 & -.06 & -.03 & -.02 & -.03 \\
\hline Age & .00 & .01 & -.04 & -.04 & -.04 & .00 & .00 & .00 & .01 & .01 & .01 \\
\hline Education & -.01 & .00 & -.01 & .00 & .00 & .04 & $.04+$ & $.04+$ & .04 & .03 & .03 \\
\hline Tenure & $.05^{+}$ & $.05^{+}$ & $.06^{+}$ & $.05^{+}$ & .04 & $-.04^{+}$ & $-.04 *$ & $-.04 *$ & $.06 *$ & $.07 *$ & $.07 *$ \\
\hline type & $.12^{+}$ & $.11^{+}$ & $.12^{+}$ & .11 & .07 & .03 & .02 & .01 & $.14^{*}$ & $.15^{*}$ & $.16^{*}$ \\
\hline \multicolumn{12}{|l|}{ Step 2} \\
\hline CJI & & $.18 * *$ & & $.19 * *$ & $.13 * *$ & & $.09 * *$ & $.07 *$ & & -.08 & -.06 \\
\hline \multicolumn{12}{|l|}{ Step 3} \\
\hline AJI & & & & & $.34 * *$ & & & $.10 * *$ & & & $-.11 *$ \\
\hline$\Delta R^{2}$ & .02 & $.03 * *$ & $.03 *$ & $.03 * *$ & $.09 * *$ & $.04 *$ & $.02 * *$ & $.02 * *$ & $.03^{+}$ & .01 & $.01 *$ \\
\hline$\Delta F$ & 1.21 & $15.06^{* * *}$ & $2.28 *$ & $14.10 * *$ & $50.69 * * *$ & $2.38 *$ & $8.20 * *$ & $10.14 * *$ & $1.93^{+}$ & 2.61 & $5.53 *$ \\
\hline
\end{tabular}

Note: $N=462$.

Dummy1 = Organization 1; Dummy2= Organization 2; CJI, cognitive job insecurity; AJI, affective job insecurity .

$* p<.05 ; *^{*} p<.01 ;{ }^{+} p<.10$ (two-tailed).

We again conducted Sobel and bootstrap tests. The results in Table 5 show that the indirect effect of cognitive JI through affective JI was significant for all Time 2 outcomes (affective JI: $Z=2.91, p<.01$; well-being: $Z=2.26$, $p<.05$; performance: $Z=1.96, p<.05$, two-tailed).

Finally, we used structure equation modeling (SEM) to test the entire model involving all the proposed relationships. Following Anderson and Gerbing's (1988) 2-stage procedure for SEM, we estimated the measurement model first and then the structural models. We conducted a confirmatory factor analysis with all of the study variables, using AMOS18.0 (Arbuckle, 2009). It included seven variables: employee involvement, employee communication, cognitive JI, affective JI (Times 1 and 2), impaired psychological well-being, and job performance. For measures with more than three items, we created three parcels to simplify the model (Mathieu \& Farr, 1991). Thus, we conducted an exploratory factor analysis to obtain each item's factor loading coefficient, then combined the items with the highest and lowest loadings until we yielded three aggregated items for each construct. The method is common practice in management research that uses SEM (Hui, Law, \& Chen, 1999; Mathieu \& Farr, 1991). The 7-factor model fits the data well $\left(\chi^{2} / d f=1.30 ; T L I=0.99 ; C F I=0.99 ; R M S E A=.03 ; S R M R=0.05\right)$ and exhibited a

Table 5. Results of Sobel and bootstrap tests of mediation effect of affective job insecurity between cognitive job insecurity and employee outcomes.

\begin{tabular}{|c|c|c|c|c|c|c|}
\hline & \multicolumn{6}{|c|}{ Indirect effect } \\
\hline & \multirow[b]{2}{*}{ Effect } & \multirow[b]{2}{*}{$S E$} & \multirow[b]{2}{*}{$Z$} & \multirow[b]{2}{*}{$p$} & \multicolumn{2}{|c|}{ Bootstrapping $(95 \% \mathrm{CI})$} \\
\hline & & & & & Lower & Upper \\
\hline $\mathrm{CJI} \rightarrow \mathrm{AJI} \rightarrow \mathrm{T} 2 \mathrm{AJI}$ & .06 & .002 & 2.91 & .00 & 0.03 & 0.11 \\
\hline $\mathrm{CJI} \rightarrow \mathrm{AJI} \rightarrow \mathrm{T} 2$ impaired psychological well-being & .02 & 0.01 & 2.26 & .02 & 0.01 & 0.04 \\
\hline $\mathrm{CJI} \rightarrow \mathrm{AJI} \rightarrow \mathrm{T} 2$ job performance & -.02 & 0.01 & 1.96 & .05 & -0.05 & -0.00 \\
\hline
\end{tabular}

Note: $N=462$. CJI, cognitive job insecurity; AJI, affective job insecurity; SE, standard error; CI, confidence interval. 
significantly better model fit than a 6-factor model that combines involvement and communication $\left[\Delta \chi^{2}\right.$ $(6)=405.71, p<.001]$, a 6 -factor model that combines cognitive and affective JI measured at Time $1\left[\Delta \chi^{2}\right.$ $(6)=149.60, p<.001]$, and a 5 -factor model that combines cognitive and affective JI measured at Times 1 and 2 $\left[\Delta \chi^{2}(11)=699.60, p<.001\right]$. We then continue to test the structural models on the basis of the measurement model.

As we show in Table 6, we tested the proposed model and three alternative models. All the models include paths from employee involvement and employee communication to cognitive JI and from affective JI to all Time 2 variables (affective JI, psychological well-being, and job performance). All latent exogenous variables were let to covary with each other. Because the set of control variables did not correlate high with the dependent variables, they were not included in the SEM, to simplify the model. We performed parceling in the SEM, as in the confirmatory factor analysis. In Model 1, we added paths from cognitive JI to the outcomes but no link between cognitive and affective JI. Results show that the model fit well $\left(\chi^{2} / d f=1.55 ; T L I=0.98 ; C F I=0.98 ; R M S E A=0.03 ;\right.$ SRMR $\left.=0.06\right)$. In Model 2, we added a path from cognitive JI to affective JI but no link between cognitive JI and the outcomes. Results show that the model fit well $\left(\chi^{2} / d f=1.48 ; T L I=0.98 ; C F I=0.98 ; R M S E A=0.03 ; S R M R=0.06\right)$ and did not differ significantly from Model $1\left[\Delta \chi^{2}(4)=6.02, n s\right]$. In Model 3, we added both paths from cognitive JI to affective JI and from cognitive JI to the outcomes, which represents the proposed partial mediation model. Results show that the model fit well $\left(\chi^{2} / d f=1.47 ; T L I=0.98 ; C F I=0.98 ; R M S E A=0.03 ; S R M R=0.06\right)$ and improved significantly from both Models $1\left[\Delta \chi^{2}(1)=13.57, p<.001\right]$ and $2\left[\Delta \chi^{2}(3)=7.85, p<.05\right]$.

We summarize the results of the SEM analysis and model comparison in Figure 1 and in Table 6. Overall, the SEM results are consistent with the previous regression results. As shown in Figure 1, the path coefficient is significant for the link between employee involvement and cognitive JI $(\beta=-.14, p<.05)$ but not for the path between organizational communication and cognitive $\mathrm{JI}(\beta=.06, n s)$; the cognitive JI and affective JI link is significant

Table 6. Summary of model fit indexes of the models.

\begin{tabular}{|c|c|c|c|c|c|c|c|}
\hline Model test & $\chi^{2}$ & $d f$ & $\chi^{2} / d f$ & $C F I$ & $T L I$ & $S R M R$ & RMSEA \\
\hline M0: (measurement model) & 220.09 & 168 & 1.31 & 0.99 & 0.99 & 0.03 & 0.03 \\
\hline M1: no link between CJI and AJI & 306.00 & 198 & 1.55 & 0.98 & 0.98 & 0.06 & 0.03 \\
\hline $\mathrm{M} 2: \mathrm{CJI} \rightarrow \mathrm{AJI}$ & 299.98 & 202 & 1.48 & 0.98 & 0.98 & 0.06 & 0.03 \\
\hline $\begin{array}{l}\text { M3: CJI } \rightarrow \text { AJI; direct links from CJI to outcomes } \\
\text { (proposed partial mediation model) }\end{array}$ & 292.13 & 199 & 1.47 & 0.98 & 0.98 & 0.06 & 0.03 \\
\hline
\end{tabular}

Note: In Models 1-3, there are direct links from involvement and communication to CJI, and direct links from AJI to outcomes. CJI, cognitive job insecurity; AJI, affective job insecurity.

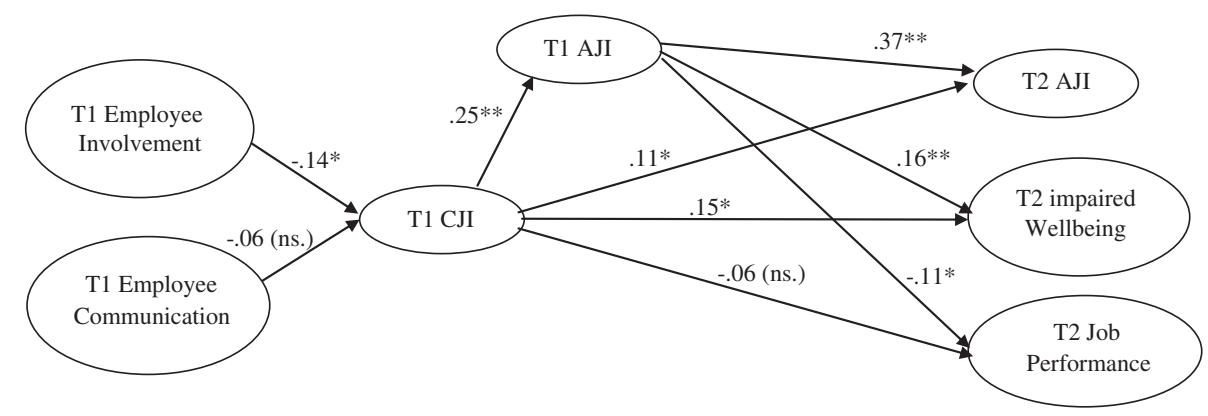

Figure 1. Results of structure equation modeling test of the job insecurity process model. Note: Standard coefficient was reported; CJI, cognitive job insecurity; AJI, affective job insecurity. ${ }^{*} p<.05 ; * * p<.01$ 
( $\beta=-.25, p<.01$ ); affective JI has significant effects on all the three outcomes (Time 2 affective JI $\beta=.37, p<.01$; impaired well-being $\beta=.16, p<.01$; job performance $\beta=-.11, p<.05$ ) whereas cognitive JI has significant impact on Time 2 affective JI and impaired psychological well-being but not job performance (Time 2 affective JI $\beta=.11$, $p<.05$; impaired well-being $\beta=.15, p<.05$; job performance $\beta=-.06, n s$ ).

\section{Discussion}

We have proposed a model of the JI process to extend scarce investigations into the relationships of affective versus cognitive JI with various antecedents and outcomes. Our proposed model specifies that organizational practices, including employee involvement and communication, influence the level of cognitive JI. Cognitive JI then is associated with more affective JI, which influences individual psychological and behavioral outcomes.

This study makes several theoretical contributions. First, we develop and test a more comprehensive conceptual model of the JI process, in which we include antecedents of cognitive and affective JI. By testing a comprehensive model in one study, we get a better understanding of the phenomena-organizational practices influence employee outcomes through affecting employees' perceptions and experiences of JI. In this sense, JI is one perspective that can be used to understand organizational behavior.

Second, we confirm the construct validity of affective JI by demonstrating the validity and reliability of our affective JI scale. In our literature reviews, we found very few studies that use both cognitive and affective conceptualizations (e.g., Borg \& Elizur, 1992; Ito \& Brotheridge, 2007; see Huang et al., 2010). Moreover, the few studies that exist have been cross-sectional, with limited evidence to substantiate a valid measure of affective JI. Therefore, we provide a good measure of affective JI that researchers should prefer over scales whose construct validity has not been examined. The retest reliability of our affective JI measure is moderate $(r=.35, p<.01)$. Thus, we find some degree of stability in people's emotions about JI once they experience them, but we also suggest that situational effects in the six months between the two measurement periods could explain the remainder of the variance in affective JI in Time 2. Additional studies should examine how people cope with their affective JI over time in various contexts.

Third, in supporting the discriminant validity of affective JI from cognitive JI initially suggested by Huang et al. (2010), we show that cognitive JI relates positively to affective JI over time but is distinct from emotional reactions. The moderate correlation between cognitive JI and affective JI suggests that the two constructs are not redundant. Furthermore, we identify different antecedents and outcomes of cognitive JI and affective JI. Whereas cognitive JI relates to organizational practices, affective JI mediates the cognitive JI-outcomes relationships. Moreover, we extend the research of Huang et al. (2010), in which they showed that affective JI mediates the effects of cognitive JI on outcomes, in that we study a different set of outcomes and, more importantly, clarify that cognitive JI continues to play an important role in the process. It partially mediates the effects of organizational practices on affective JI, as well as directly and indirectly influencing outcomes over time. Organizational employee involvement practices relate negatively to employees' cognitive JI perceptions, which then relate positively to the affective experience of JI.

Fourth, this study is among the first to examine the impact of employee involvement and communication on employee cognitive and affective JI (e.g., Vander Elst et al., 2010). Although communication with employees did not produce the predicted effect for our sample, this result may reflect the high correlation between employee involvement and organizational communication; when we examined communication in a separate regression, its effect on cognitive JI was significant $(\beta=-.17, p<.01)$. These findings are consistent with the perceived control argument (Greenberger \& Strasser, 1986) and the appraisal theory of emotion and stress (Folkman \& Lazarus, 1985; Lazarus \& Folkman, 1984); an environment that a person appraises as relevant and threatening constitutes a source of stress. However, when organizations involve employees in their procedures, employees' perceptions of personal control encourage them to appraise the work environment as less threatening, so they experience fewer negative emotions regarding job security. Thus, management practices such as employee involvement affect 
individual and organizational outcomes through their mitigating impact on cognitions about insecurity and, by implication, their affective reactions. Further research must continue to examine organizational antecedents that can help decrease employees' perceptions of JI.

Fifth, we find different links from cognitive and affective JI to employees' impaired psychological well-being and job performance. Affective JI predicts both psychological well-being and job performance, consistent with our expectation of detrimental impacts of affective JI. Cognitive JI has an indirect effect on performance through affective JI, but it directly predicts only psychological well-being. Thus, the effect of cognitive JI on job performance appears quite complicated. Although direct effects should capture employees' negative reactions to an imbalanced social exchange (i.e., the organization offers less job security), the relationships also could be nonlinear [e.g., the U-shape relationship between JI and work effort found in Brockner et al. (1992)], moderated by organizational or individual factors such as organizational justice, dispositional factors such as locus of control or negative affectivity, individual attributions of JI, or coping strategies that enhance or attenuate negative responses. Additional research should consider other potential consequences of cognitive and affective JI and possible moderators. As Rosenblatt and Ruvio (1996) note, understanding how employees experience JI leads to a better understanding of its impact on organizational effectiveness, whether in normal periods or in crises.

Sixth, we conducted our research in China, a setting that deserves more research attention. The trend of organizational restructuring - in the forms of corporate downsizing, mergers and acquisitions, plant closures, and workforce reorganizations-has expanded to the global workforce (Probst \& Lawler, 2006). In particular, the Chinese economy has undergone significant reforms in the past two decades, shifting from an "iron rice bowl" policy of lifetime employment to a market-oriented setting. The economic reforms have had significant impacts on employment security among Chinese workers. Furthermore, China offers a particularly appropriate context to test claims that people from collectivist cultures react more negatively to the threat of job loss than do individualists, because of their greater emphasis on group ties, higher need for affiliation, and preferences for security (Probst \& Lawler, 2006). However, JI research thus far has been conducted almost exclusively in the west (cf. Huang et al., 2010; Lee et al., 2006, 2008; Wong et al., 2005). We studied three state-owned enterprises in China, where the level of job security generally should be higher than in other types of Chinese organizations, such as joint ventures or private companies. Our study thus offers a conservative test, and our results suggest that JI is ubiquitous in China.

If both cognitive JI and affective JI exist even in a relatively unthreatening environment, as the results of this study indicate, JI should be an ongoing managerial concern. Because JI affects employee outcomes negatively, management's challenge is to identify and treat its sources. Our findings indicate that employee involvement practices can influence employees' sense-making processes with regard to job security. Moreover, if the distinction between cognitive JI and affective JI found in this study receive adequate support in future research, it is meaningful to study moderators between the two-individual difference factors or organizational interventions that may prevent cognitive perceptions from producing harmful emotions.

However, these findings also need to be considered in light of several limitations. Our design is correlational, so we cannot draw causal conclusions. We tested some relationships using a time-lagged design, such that we measured some employee outcomes six months after we collected our initial data. Compared with existing literature, our design offers stronger support for our findings and provides important construct validity evidence regarding affective JI and the differential effects of cognitive and affective JI on outcomes. Because we proposed affective JI as both an outcome of cognitive JI and a mediator between cognitive JI and the outcomes, we measured affective JI at both Times 1 and 2 but measured cognitive JI only at Time 1. Further studies also should use a cross-lagged panel longitudinal design to measure both constructs at both times and thus further examine the dynamic relationship between cognitive JI and affective JI. For example, it might be interesting to examine the conditions in which respondents reappraise their cognitive JI levels and regulate their emotions, suggested by Gross's (1998) model of emotional regulation.

Another limitation is the self-reported nature of our measures, which may contribute to common method bias. However, we tried to minimize this bias by using multiple sources, such that job performance was assessed by supervisors. Our use of a time-lagged design also should reduce the method bias in our findings. In addition, we calculated 
the variance explained by the method factor following Williams, Cote, and Buckley (1989). Results show that the variance explained was 6.8 percent, which was much lower than the 25 percent observed in William et al. (1989), suggesting that common method variance is not a pervasive problem in this study. That being said, additional studies that assess organizational practices more objectively and test outcomes using different sources of data would be desirable.

In conclusion, our findings suggest that employers must pay attention to organizational practices, such as employee involvement, that can help minimize JI perceptions. These practices lower perceptions of JI, perhaps by increasing perceptions of personal control; they also have secondary effects on employees' affect. Employees with negative emotional reactions to perceived threats to their job security eventually begin to engage in negative employee outcomes. Employers therefore should attend to both cognitive appraisals and emotional reactions. We call for ongoing research that continues to examine the differential effects of cognitive JI and affective JI and their interrelationships and thus clarifies the consequences of these two forms of JI for both organizations and employees.

\section{Author biographies}

Guo-hua Huang, PhD, is currently an assistant professor in the Department of Management at the Hong Kong Baptist University. Her major research interests include emotion in organizations, emotional intelligence, identity and self-concept at workplace, stress and coping, and job insecurity.

Xiongying Niu, PhD, is a professor in Human Resource Management Department, Business School, University of International Business \& Economics. His research interests include organizational change, cross-cultural human resource development, creativity, employment, and job insecurity.

Cynthia Lee, $\mathrm{PhD}$, is the chair professor of the Department of Management and Marketing, The Hong Kong Polytechnic University and a professor of the Management and Organizational Development Group, Northeastern University. Her research interests primarily focus on the study of organizational behavior in Chinese contexts (such as managing change and innovation, performance management, and job insecurity).

Susan Ashford, PhD, is the Michael and Susan Jandernoa Professor of Organizational Behavior and Human Resource Management at the University of Michigan Business School. She is a fellow of the Academy of Management. Her research interests include managerial effectiveness, issue selling, self-management, feedback seeking, and nonstandard work.

\section{References}

Adkins, C. L., Werbel, J. D., \& Farh, J.-L. (2001). A field study of job insecurity during a financial crisis. Group \& Organization Management, 26, 463-483.

Anderson, J. C., \& Gerbing, D. W. (1988). Structural equation modeling in practice: A review and recommended two-step approach. Psychological Bulletin, 103(3), 411-423.

Arbuckle, J. L. (2009). Amos (version 18.0) [Computer program]. Chicago, IL: SPSS.

Ashford, S. J., Lee, C. L., \& Bobko, P. (1989). Content, causes, and consequences of job insecurity: A theory-based measure and substantive test. Academy of Management Journal, 32, 803-829.

Bernardi, R. A. (1994). Validating research results when Cronbach's alpha is below .70: A methodological procedure. Educational and Psychological Measurement, 54, 766-775.

Borg, I., \& Elizur, D. (1992). Job insecurity: Correlates, moderators and measurement. International Journal of Manpower, 13(2), 13-26.

Brislin, R. W. (1980). Translation and content analysis of oral and written material. In H. C. Triandis, \& J. W. Berry (Eds.), Handbook of cross-cultural psychology, 2, 389-444. Boston, MA: Allyn and Bacon.

Brockner, J., Grovner, S., Reed, T. F., \& DeWitt, R. L. (1992). Layoffs, job insecurity, and survivors' work effort: Evidence of an inverted-U relationship. Academy of Management Journal, 35(2), 413-425. 
Capelli, P. (1999). Career jobs are dead. California Management Review, 42(1), 146-167.

Caplan, R. D., Cobb, S., French, J. R. P., Jr., Van Harrison, R. V., \& Pinneau, S. R., Jr. (1975). Job demands and worker health: Main effects and occupational differences. Washington, D.C.: U.S. Department of Health, Education, and Welfare.

Cheng, G. H.-L., \& Chan, D. K.-S. (2008). Who suffers more from job insecurity? A meta-analytic review. Applied Psychology: An International Review, 57, 272-303.

Cortina, J. M. (1993). What is coefficient alpha? An examination of theory and applications. Journal of Applied Psychology, $78,98-104$.

De Whitte, H. (2005). Job insecurity: Review of the international literature on definitions, prevalence, and antecedents and consequences. Journal of Industrial Psychology, 31, 1-6.

De Witte, H. (2000). Arbeidsethos en jobonzekerheid: Meting en gevolgen voor welzijn, tevredenheid en inzet op het werk [Work ethic and job insecurity: Assessment and consequences for well-being, satisfaction and performance at work]. In R. Bouwen, K. De Witte, H. De Witte, \& T. Taillieu (Eds.), Van groep naar gemeenschap [From group to community]. Liber Amicorum Prof. Dr. Leo Lagrou (pp. 325-350). Leuven: Garant.

Folkman, S., \& Lazarus, R. (1985). If it changes it must be a process: Study of emotion and coping during three stages of a college examination. Journal of Personality and Social Psychology, 48, 150-170.

Frijda, N. H. (1993). Moods, emotion episodes and emotions. In M. Lewis, \& J. M. Haviland (Eds.), Handbook of Emotions (pp. 381-404). New York, NY: Guildford Press.

Goldberg, D. P., \& Hillier, V. F. (1979). A scaled version of the General Health Questionnaire. Psychological Medicine, 9, $139-145$.

Greenberger, D. B., \& Strasser, S. (1986). The development and application of a model of personal control in organizations. Academy of Management Review, 11, 164-177.

Greenhalgh, L., \& Rosenblatt, Z. (1984). Job insecurity: Toward conceptual clarity. Academy of Management Review, 9, $438-448$.

Gross, J. J. (1998). The emerging field of emotion regulation: An integrative review. Review of General Psychology, 2, 271-299.

Hair, J. F., Jr., Anderson R. E., Tatham R. L., \& Black W. C.. 1998. Multivariate data analysis with readings (5th ed.). Englewood Cliffs, NJ: Prentice Hall.

Hellgren, J., Sverke, M., \& Isaksson, K. (1999). A two-dimensional approach to job insecurity: Consequences for employee attitudes and well-being. European Journal of Work and Organization Psychology, 8, 179-195.

Huang, G., Lee, C., Ashford, S., Chen, Z., \& Ren, X. (2010). Affective job insecurity: A mediator of the cognitive job insecurity and employee outcomes relationships. International Studies of Management and Organizations, 40, $20-39$.

Hui, C., Law, K. S., \& Chen, Z. X. (1999). A structural equation model of the effects of negative affectivity, leader-member exchange, and perceived job mobility on in-role and extra-role performance: A Chinese case. Organizational Behavior and Human Decision Processes, 77, 3-21.

Ito, J. K., \& Brotheridge C. M. (2007). Exploring the predictors and consequences of job insecurity's components. Journal of Managerial Psychology, 22(1), 40-64.

James, L. R. (1982). Aggregation bias in estimates of perceptual agreement. Journal of Applied Psychology, 67, $219-229$.

Johnson, C. D., Messe L. A., \& Crano W. D. (1984). Predicting job performance of low income workers: The work opinion questionnaire. Personnel Psychology, 37, 291-299.

Kets de Vries, M. F. R., \& Balazs, K. (1997). The downside of downsizing. Human Relations, 50(1), 11-50.

Kizilos, M. A., \& Cummings, T. G. (1994). Achieving superior service through employee involvement: An empirical investigation. Academy of Management Best Paper Proceedings.

König, C. J., \& Staufenbiel T. (2006). The difference between cognitive and affective job insecurity. Paper presented at the 21st annual conference of the Society for Industrial and Organizational Psychology, Dallas, TX.

Lawler, E. E., III. (1992). The ultimate advantage: Creating the high involvement organization. San Francisco, CA: Jossey-Bass.

Lawler, E. E., III. (1986). High involvement management. San Francisco: Jossey-Bass.

Lawler, E. E. (1996). High-involvement management: Participative strategies for improving organizational performance. San Francisco, CA: Jossey-Bass.

Lawler, E. E., III, Mohrman, S. A., \& Ledford, G. E. (1995). Creating high performance organizations. San Francisco, CA: Jossey-Bass.

Lazarus, R. S. (1999). Stress and emotion: A new synthesis. New York, NY: Springer.

Lazarus, R. S., \& Folkman, S. (1984). Stress, appraisal, and coping. New York, NY: Springer.

Leana, C. R., \& Florkowski, G. W. (1992). Employee involvement programs: Integrating psychological theory and management practice. Research in Personnel and Human Resources Management, 10, 233-270.

Lee, C., Bobko, P., Ashford, S. J., Chen, Z. X., \& Ren, X. P. (2008). Cross-cultural development of an abridged job insecurity measure. Journal of Organizational Behavior, 29, 373-390.

Lee, C., Bobko, P., \& Chen, Z. X. (2006). Investigation of the multidimensional model of job insecurity in two countries. Applied Psychology: An International Review, 55, 167-195. 
Lee, C., Jamieson, L. F., \& Earley, P. C. (1996). Beliefs and fears and type A behavior: Implications for academic performance and psychiatric health disorder symptoms. Journal of Organizational Behavior, 17, 151-177.

MacKinnon, D. P., Lockwood, C. M., Hoffman, J. M., West, S. G., \& Sheets, V. (2002). A comparison of methods to test the significance of the mediated effect. Psychological Methods, 7, 83-104.

Mathieu, J. E., \& Farr, J. L. (1991). Further evidence for the discriminant validity of measures of organizational commitment, job involvement, and job satisfaction. Journal of Applied Psychology, 76(1), 127-133.

Morrison, E. W., \& Robinson S. L. (1997). When employees feel betrayed: a model of how psychological contract violation develops. Academy of Management Review, 22, 226-256.

Natti, J., Happonen, M., Kinnunen, U., \& Mauno, S. (2005). Job insecurity, temporary work and trade union membership in Finland 1977-2003. In H. De Witte (Ed.), Job insecurity, union involvement and union activism (pp. 11-48). Aldershot: Ashgate.

Nunnally J. C. (1967). Psychometric theory (1st ed.). New York, NY: McGraw-Hill.

Pierce, J. L., Gardner, D. G., Dunham, R. B., \& Cummings, L. L. (1993). Moderation by organization-based self-esteem of role condition-employee response relationships. Academy of Management Journal, 36, 271-288.

Preacher, K. J., \& Hayes, A. F. (2004). SPSS and SAS procedures for estimating indirect effects in simple mediation models. Behavior Research Methods, Instruments, \& Computers, 36, 717-731.

Preacher, K. J., \& Hayes, A. F. (2008). Asymptotic and resampling strategies for assessing and comparing indirect effects in multiple mediator models. Behavior Research Methods, 40(3), 879-91.

Probst, T. M. (2003). Development and validation of the Job Security Index and the Job Security Satisfaction scale: A classical test theory and IRT approach. Journal of Occupational and Organizational Psychology, 76, 451.

Probst, T. M. (2005). Countering the negative effects of job insecurity through participative decision making: Lessons from the demand-control model. Journal of Occupational Health Psychology, 10, 320-329.

Probst, T. M., \& Lawler, J. (2006). Cultural values as moderators of the outcomes of job insecurity: The role of individualism and collectivism. Applied Psychology: An International Review, 55, 234-254.

Probst, T. M., Stewart, S. M., Gruys, M. L., \& Tierney, B. W. (2007). Productivity, counterproductivity and creativity: The ups and downs of job insecurity. Journal of Occupational and Organizational Psychology, 80(3), 479.

Reisel, W. D., \& Banai, M. (2002). Job insecurity revisited: Reformulating with affect. Journal of Behavioral and Applied Management, 4, 87-91.

Rhoades, L., \& Eisenberger, R. (2002). Perceived organizational support: A review of the literature. Journal of Applied Psychology, 87, 698-714.

Richardson, H. A., \& Vandenberg, R. J. (2005). Integrating managerial perceptions and transformational leadership into a workunit level model of employee involvement. Journal of Organizational Behavior, 26, 561-589.

Riordan, C. M., Vandenberg, R. J., \& Richardson, H. A. (2005). Employee involvement climate and organizational effectiveness: An organizational system perspective. Human Resource Management, 44, 471-488.

Roseman, I. J. (1984). Cognitive determinants of emotion: A structural theory. Review of Personality and Social Psychology, $5,11-36$.

Roseman, I. J. (1991). Appraisal determinants of discrete emotions. Cognition and Emotion, 5, 161-200.

Rosenblatt, Z., \& Ruvio, A. (1996). A test of multidimensional model of job insecurity: The case of Israeli teachers. Journal of Organizational Behavior, 17, 587-605.

Rosenblatt, Z., I. Talmud, \& Ruvio, A. (1999). A gender-based framework of the experience of job insecurity and its effects on work attitudes. European Journal of Work and Organizational Psychology, 8, 197-217.

Roskies, E., Louis-Guerin, C., \& Fournier, C. (1993). Coping with job insecurity: How does personality make a difference? Journal of Organizational, 14, 616-30.

Rupp, D. E., \& Spencer S.. 2006. When customers lash out: The effects of customer interactional injustice in emotional labor and the mediating role of discrete emotions. Journal of Applied Psychology, 91, 971-978.

Schweiger, D. M., \& DeNisi, A. S. (1991). Communication with employees following a merger: A longitudinal field experiment. Academy of Management Journal, 34, 110-135.

Shackman, G. 2001. Sample size and design effect.. Presented at Albany Chapter of American Statistical Association. Retrieved from http://faculty.smu.edu/slstokes/stat6380/deff\%20doc.pdf

Smidts, A., Pruyn, A. Th. H., \& van Riel, C. B. M. (2001). The impact of employee communication and perceived external prestige on organizational identification. Academy of Management Journal, 49(5), 1051-1062.

Smith, C. A., \& Ellsworth, P. C. (1985). Patterns of cognitive appraisal in emotion. Journal of Personality and Social Psychology, 48, 813-838.

Sobel, M. E. (1982). Asymptotic intervals for indirect effects in structural equations models. In S. Leinhart (Ed.), Sociological methodology (pp. 290-312). San Francisco, CA: Jossey-Bass.

Spector, P. E., \& Fox, S. (2002). An emotion-centered model of voluntary work behavior: Some parallels between Counterproductive Work Behavior (CWB) and Organizational Citizenship Behavior (OCB). Human Resource Management Review, 12, 269-292. 
Staufenbiel, T., \& König, C. J. (2010). A model for the effects of job insecurity on performance, turnover intention, and absenteeism. Journal of Occupational and Organizational Psychology, 83, 101-117

Steiger, J. H. (1980). Tests for comparing elements of a correlation matrix. Psychological Bulletin, 87, $245-251$.

Sverke, M., J. Hellgren, \& K. Näswall. (2002). No security: A meta-analysis and review of job insecurity and its consequences. Journal of Occupational Health Psychology 7, 242-264.

Tsui, A. S., Pearce, J. L., Porter, L. W., \& Tripoli, A. M. (1997). Alternative approaches to employee-organization relationships: Does investment in employees pay off? Academy of Management Journal, 40, 1089-1121.

Vandenberg, R. J., Richardson, H. A., \& Eastman, L. J. (1999). The impact of high involvement work processes upon organizational effectiveness: A 2nd-order latent variable approach. Group and Organization Management, 24, $300-339$.

Vander Elst, T., Baillien, E., De Cuyper, N., \& De Witte, H. (2010). The role of organizational communication and participation in reducing job insecurity and its negative association with work-related well-being. Economic and Industrial Democracy, 31, 249-264.

Wagner, J. A. (1994). Participant's effects on performance and satisfaction: A reconsideration of research evidence. Academy of Management Review, 19, 312-330.

Weiss, H. M., \& Cropanzano, R. (1996). Affective Events Theory: A theoretical discussion of the structure, causes and consequences of affective experiences at work. In B. M. Staw and L. L. Cummings (Eds.), Research in Organizational Behavior, Vol. 18 (pp. 1-74). Greenwich, CT: JAI Press.

Williams, L. J., Cote, J. A., \& Buckley, M. R. (1989). Lack of method variance in self-reported affect and perceptions at work: Reality or artifact? Journal of Applied Psychology, 74, 462-468.

Wong, Y. T., Wong, C. S., Ngo, H. Y., \& Lui, S. (2005). Different responses to job insecurity of Chinese workers in joint ventures and state-owned enterprises. Human Relations, 58(11), 1391-1418.

Zhao, X., Lynch J. G., \& Chen, Q. (2010). Reconsidering Baron and Kenny: Myths and truths about mediation analysis. Journal of Consumer Research, 37, 197-206.

\section{APPENDIX}

\section{AFFECTIVE JOB INSECURITY SCALE}

Please think about your current employer and circle the number that best describes your feelings:

1. The lack of job security in this company makes me feel nervous.

2. I feel uneasy about my chances for remaining with this company.

3. I lose sleep worrying about my future with this company.

4. I am unhappy with the amount of job security that I have with this company.

5. I am tense about maintaining my current job employment status.

6. I am very unsure that I can remain employed with this company for as long as I wish.

7. I am pessimistic about the job security with this company.

8. I am troubled by the thought of losing my job.

9. I am scared by the thought of losing my job.

10. I am worried that this company will fire me any time. 